Abhner Youssif Mota Arabi' Felipe Fernandes de Carvalho ${ }^{2}$ Marcello Caio Ramon e Barros Ferreira ${ }^{3}$
* Recebido em: fevereiro de 2012.

Aprovado em: abril de 2012.

1 Graduando em Direito pela Universidade de Brasília (UnB), Estagiário de Direito no STF abhner.ab@gmail.com

2 Graduando em Direito pela Universidade de Brasília (UnB), Estagiário de Direito na Subchefia para Assuntos Jurídicos da Casa Civil da Presidência da República - felipcarvalho@ gmail.com

3 Graduando em Direito pela Universidade de Brasília (UnB), Estagiário de Direito no STF marcelloc2@hotmail.com

\section{Terrorismo, Direito Penal do inimigo e Constitucionalismo: a tipificação do terrorismo e sua Incongruência com o Estado Democrático de Direito*}

\section{Terrorism, Criminal Law for the Enemy and Constitutionalism: the incongruity with the democratic rule of law}

\section{Resumo}

O quadro é de insurgência do Terrorismo e sua consequente inserção no Direito Penal, por sua criminalização em nome da Segurança Nacional. Surgem também polêmicas teorias como o Direito Penal do Inimigo, legitimando, assim, discursos que incorporam estas ideias, que se lançam em uma guerra ao "Eixo do Mal", que rechaçam os direitos humanos frutos de lutas de imensurável valor histórico-social e representam uma ameaça constante e real à democracia. Diante disso, este artigo pretende analisar mais amiúde as consequências jurídicas e legislativas dos atos terroristas e como se relacionam com as ideias centrais do Direito Penal do Inimigo, evidenciando os perigos disfarçados em um discurso de segurança nacional e combate ao terrorismo (especialmente pós 11 de setembro) que ele representa ao próprio Direito, como este é entendido hoje; e apontando sua incompatibilidade com o constitucionalismo em que se encontra imersa a sociedade ocidental e seus ideais basilares de inclusão, igualdade e universalização de direitos.

Palavras-chave: Democracia. Terrorismo. Direito Penal do Inimigo. Constitucionalismo.

\begin{abstract}
The context is the insurgency of Terrorism and its subsequent inclusion into the Criminal Law theme, by its criminalization in the name of national security. Also rises controversial theories such as the Criminal Law for the Enemy, legitimizing those discourses that incorporate these ideas, which are engaging in a war against the "Axis of Evil", rejecting the human rights, these ones, fruits of a really historical and social valuable struggle, and represents a constant and real threat to democracy. Thus, this article intends to analyze more thoroughly this Criminal Law for the Enemy, highlighting the dangers disguised in the speech of national security and fighting terrorism (especially after September 11) it represents to Law itself, as we think it nowadays; and pointing its incompatibility with constitutionalism in which Western society is immersed and its basic ideals of inclusion, equality and universal rights.
\end{abstract}

Keywords: Democracy. Terrorism. Criminal Law for the Enemy. Constitutionalism. 


\section{Introdução}

A justiça é uma loucura, uma experiência do impossível, afirma Derrida ${ }^{4}$. Essa é uma afirmação central, porque põe em xeque a ideia de justiça, esclarecendo que ela é inalcançável, por um motivo muito simples: a justiça, e o Direito, por tabela, necessitam de força. Eles são força de lei. E a força é uma violência, é a pena imposta, é o retributivo penal inafastável, é a decisão. O Direito é visceralmente violento. “Trata-se sempre de limitar a pior violência por outra"s, o que é percebido não só por ele, Direito, ser sanção, mas porque é em essência um corte argumentativo. E isso se agrava com o Direito Penal, principalmente ao se pensarem os discursos políticos sobre o fenômeno do terrorismo, especificamente os baseados na ideia de Direito Penal do Inimigo, o que pode ser sentido, por exemplo, nas reações no âmbito legislativo do Ocidente em geral a esse fenômeno.

O senso comum, todavia, costuma ir justamente de encontro ao entendimento dessa identidade entre Direito e violência, de modo a ser dissimulado no ideário social contemporâneo. Segundo o ensinamento clássico, a temida anarquia seria uma consequência natural, não fosse a mão pesada do Estado, o que fez com que a publicização do Direito Penal passasse a ser compreendida como a solução. "Com efeito, a lei penal protege, em primeiro plano, o interesse da ordem jurídica geral, cujo titular é o Estado e, secundariamente, o interesse do particular", algo que, como Derrida pontua, pode ser lido como a prática, em nome do Direito, de uma violência conservadora - isto é, uma violência que garante e mantém a aplicabilidade do Direito - a fim de se evitar que uma nova violência fundadora - transformadora e legitimadora de relações de direito , como a que deu origem à conservadora - se perpetre. Seja lá como for, com o paradigma do individualismo iluminista, sedimentou-se a noção de que "o Direito Penal regula as relações dos indivíduos em sociedade e as relações destes com a mesma sociedade" ${ }^{\prime \prime}$, entendimento trouxe inúmeros avanços - es-

\footnotetext{
${ }^{4}$ Cf. DERRIDA, Jacques. Força de lei: o fundamento mítico da autoridade. São Paulo: WMF M. Fontes, 2010.

5 Ibidem, p. 115.

6 BITENCOURT, Cezar Roberto. Tratado de direito penal: parte especial. 5. ed. São Paulo: Saraiva, 2011. p. 40.

7 Ibidem, p. 33.
}

pecialmente a partir do "garantismo"" - para a noção de indivíduo e de garantias individuais.

Em decorrência disso e do processo histórico que se seguiu, tem-se hoje todo um panorama dos chamados direitos humanos ou fundamentais e do entendimento de inclusão, garantismo, constitucionalismo, democracia substancial, ou, resumindo em um só termo, vive-se o paradigma do sempre pretenso Estado Democrático de Direito. A democracia vê e reconhece no "todos", como afirma o artigo $1^{\circ}$ da Declaração Universal dos Direitos Humanos, o outro, a alteridade, e tem lugar a afirmação do diferente enquanto igual em dignidade e direitos, ou, como quer Dworkin, dá-se vez à igualdade substantiva, considerando os cidadãos como iguais, dignos e merecedores da mesma consideração e respeito entre cada um dos indivíduos, como norte da experiência social democrática ${ }^{9}$.

No contexto ocidental, porém, na contramão, a violência de que trata Derrida se agrava muito com um agigantamento do Direito Penal - como mostra, por exemplo, a edição da lei crimes hediondos -. No próprio Código Penal (em vigor desde 1940) se vê isso: as disposições desse ordenamento, quase sempre presentes nos discursos sociais veiculados pela mídia que clamam por justiça, são igualmente violência, muito embora a sociedade, como um todo, não enxergue assim, e mostram-se em certa medida incongruentes com os princípios democráticos e republicanos endossados pela Constituição Federal de 1988. Cogita-se, há muito, reformá-lo, trazendo uma maior compatibilidade com a Carta Constitucional, a despeito de uma ampla reforma da parte geral ocorrida

\footnotetext{
8 Acerca da ideia de garantismo penal, Ferrajoli destaca três possibilidades de entendimento desse conceito. O primeiro trata do modelo normativo de estrita legalidade do direito penal; o segundo, aborda a separação do ser e do dever ser do direito penal; o último, já se aproxima de uma filosofia política que requer do Direito e do Estado o ônus da justificação externa com base nos bens e nos interesses dos quais a tutela constitui finalidade. Diante da proposta deste trabalho, aproximamo-nos do primeiro e do terceiro entendimento elencados pelo jurista italiano. Para nós, garantismo penal nada mais é do que a mistura de um conceito prático com outro abstrato - valorativo, o primeiro relacionado a uma técnica de aplicação do direito que obedece estritamente à lei, o segundo, à proteção do indivíduo diante do ônus que o aparato jurídico e político tem para direta ou indiretamente reprimir a liberdade do homem.

9 Cf. DWORKIN, Ronald. Levando os direitos a sério. 3. ed. São Paulo: WMF M. Fontes, 2010.
} 
em 1984 e de edições de diversas leis que alteraram ou revogaram alguns dos dispositivos do Código Penal.

Nesse quadro, instituiu-se, em outubro de 2011, uma comissão para compor um projeto de reforma do Código Penal, com a previsão da apresentação de um anteprojeto em maio de 2012. Essa insurgência se deve, em parte, à aproximação de eventos como a Copa do Mundo de 2014 e as Olimpíadas de 2016. Alega-se que, se não houver tipificação penal do terrorismo, eventuais ações estatais necessárias seriam dificultadas. No âmbito dessa comissão, presidida pelo ministro Gilson Dipp, têm sido propostas algumas mudanças e inovações, destacando-se a criminalização dos “atos de terrorismo", revogando a Lei de Segurança Nacional, ideia surgida mediante proposta do Conselho Nacional dos Secretários de Segurança Pública, que defendia, entre outras coisas, a criminalização de condutas como participação em milícias e atos de terrorismo. A proposta é que se crie o crime de terrorismo, cominando-se pena restritiva de liberdade de 8 a 15 anos, excetuando-se os movimentos sociais - não considera terrorismo condutas individuais ou coletivas de "pessoas movidas por propósitos sociais" ou, segundo palavras do relator (o procurador Luiz Carlos Gonçalves), “a lei não se aplicará a movimentos sociais com meios lícitos -, algo já aprovado no anteprojeto, possibilitando-se interpretar tal possível guinada legislativa dentro de um contexto maior e global da expansão de teorias como o Direito Penal do Inimigo, que tem em Gunther Jakobs seu grande expoente.

Nesse ponto, é interessante notar, voltando ao contexto ocidental como um todo, que se está abdicando, de maneira geral, do princípio do Direito Penal mínimo, ao ponto de se chegar a esse referido produto peculiar extremo da própria modernidade, de que se lança mão, que é justamente a ideia de Direito Penal do Inimigo, o qual surge como uma promessa, um esboço de solução para a questão do terrorismo, isto é, uma resposta enérgica, vigorosa, aos possíveis ataques terroristas, ameaçadores da ordem, representada em um discurso de repressão que se legitima na identificação do inimigo terrorista e no combate a ele por meio da promulgação de leis que aspiram a aumentar a segurança, muito embora constituam, elas mesmas, grandes riscos à democracia. E aí se instaura o problema: o confronto do Estado Democrático de Direito com esse Direito Penal do Inimigo, que se utiliza exatamente do mesmo ideal de diferença pra justificar sua própria existência.
Deve-se notar que o Direito Penal do Inimigo, sob um prisma estritamente pragmático, recorre basicamente ao desejo de vingança de indivíduos que necessitam de identificar em algo concreto - no caso, outros indivíduos, ainda que jamais os tenham visto - seus medos, sua ira, suas frustrações, ou seja, trata-se da insegurança ontológica. É a personificação do medo. E o que ocorre hodiernamente é a proliferação de insegurança difusa, de tal sorte que a própria natureza das questões a serem confrontadas, como assinala Bauman, constitui-se em uma impossibilidade para soluções definitivas: “[...] pessoas que se sentem inseguras, preocupadas com o que lhes reserva o futuro e temendo pela própria incolumidade não podem realmente assumir os riscos que a ação coletiva exige" ${ }^{10}$.

As consequências disso podem ser sentidas, sobretudo, na tendência a arranjar culpados. Esse estado de ânimo permite projetar o que está nas partes “inferiores e desconfortáveis de nós mesmos” sobre o outro, "essencializando-o" e, finalmente, culpando-o por defeitos sociais sistêmicos. A "sede de justiça" se transforma em condenação sem processo, em exercício arbitrário das próprias razões, mas, pior, institucionaliza-se e legitimase, por exemplo, na figura da polícia, que, como afirma Derrida, é força de lei, tem força de lei, inventando e se atribuindo o Direito toda vez que este é suficientemente indeterminado, comportando-se como o legislador da modernidade ${ }^{11}$.

Deste modo, preparado está o terreno no qual prolifera o discurso que legitima uma permanente política de violação dos direitos humanos. O medo nos levou a consolidar o modelo do Estado de Exceção, em que as medidas preventivas são desmedidas e assombrosas. A insegurança e a vulnerabilidade que pairam sobre a sociedade falseiam o problema para oferecer respostas incompatíveis com os valores democráticos e dos direitos fundamentais, porquanto as questões da esfera pública tendem a se deslocar cada vez mais para o âmbito do direito penal, cuja solução - repressora e simbólica - induz o mal que pretende curar. A insegurança ontológica é explosiva, em suma, porque afeta sobremaneira a percepção individual do outro. Se, no Estado Democrático de

${ }^{10}$ BAUMAN, Zygmunt. Em busca da política. Trad. Marcus Penchel. Rio de Janeiro: J. Zahar Editor, 2000. p. 13.

${ }^{11}$ Cf. DERRIDA, Jacques. Força de lei: o fundamento mítico da autoridade. São Paulo: WMF M. Fontes, 2010. p. 99 
Direito, o outro é a pessoa ainda não integrada, que deve ser incorporado e reconhecido como sujeito de direitos, a manipulação da insegurança difusa inverte toda essa lógica, e o outro passa a ser percebido pela sociedade como ameaça, devendo ser isolado socialmente ou neutralizado quando o isolamento não for suficiente.

É nesse sentido que o Direito Penal do Inimigo, através do medo (que é tratado como instintos de proteção racionais), vem rotular o outro como inimigo, instaurando, por assim dizer, um alarde jurídico, uma situação peculiar que tenta se instalar na sociedade constitucional democrática, e que tem na referida comissão de elaboração de um novo Código Penal uma ameaça por excelência a todas as garantias asseguradas pela Constituição e pela prática discursivo-inclusiva.

\section{Breves considerações sobre a problemática do Direito Penal do Inimigo}

Em síntese, a proposta do Direito Penal do Inimigo não é das mais complexas: é na identificação do inimigo que se reconhece o amigo e, por tabela, tem-se duas identidades basilares. Regimes totalitários precisam de uma imagem nítida do inimigo, eles têm que demonizar o outro a fim de criar uma identidade, técnica de governabilidade que, na verdade, é milenar, mas que não deixa de ser eminentemente moderna, porque é a utilização da tradição como manipulação. Nesse sentido afirma Umberto Eco que

[...] os únicos que podem fornecer uma identidade às nações são os inimigos. Assim, na raiz da psicologia Ur-Fascista está a 'obsessão do complô, possivelmente internacional. Os seguidores tem que ser sitiados. $\mathrm{O}$ modo mais fácil de fazer emergir um complô é fazer apelo à xenofobia [...] Ur-Fascismo não pode deixar de pregar um 'elitismo popular'. Todos os cidadãos pertencem ao melhor povo do mundo, os membros do partido são os melhores cidadãos, todo cidadão pode (ou deve) tornar-se membro do partido. Mas patrícios não podem existir sem plebeus $^{12}$.

Como exemplo principal tem-se o nazismo, mas pode-se citar ainda o Império Romano e os Bárbaros, bem como Henrique V, da Inglaterra, que via na guerra

\footnotetext{
${ }^{12}$ ECO, Umberto. O Fascismo Eterno. In: AGUIAR, Eliana; ECO, Umberto. Cinco Escritos Morais. Rio de Janeiro: Record, 2000. p. 46.
}

uma válvula de escape para a situação em que então se encontrava a melhor maneira de se evitar - segundo lição aprendida com seu pai - problemas internos no país: unir a nação em torno de um objetivo nobre e patriótico comum, ou ainda as consolidações dos estados modernos, enfim. Tudo fundado em uma ideia deturpada, porém de certa forma consolidada, de identidade. E, na verdade, tudo não passa de uma manipulação do sentimento de patriotismo que reiteradamente se traduz em lealdade e subordinação.

Esse fato, que poderia parecer esquecido em um passado mais ou menos distante, é, na verdade, muito fácil de ser percebido. Ilustrando, os imigrantes, para os europeus e norte-americanos, hoje, simbolizam a instabilidade econômica e, consequentemente, a instabilidade social, eles representam a mudança de um padrão de vida. Já mais especificamente nos Estados Unidos, mas não exclusivamente, o terrorismo representa a ameaça ao modo de vida liberal do capitalismo. Nesse país, "a guerra contra o terrorismo trabalha (ou trabalhava, para aqueles que pensam que ela já acabou) para regenerar a curto ou longo prazo as causas do mal que alegam erradicar"13. Assim, surge, no panorama internacional, o discurso de guerra ao terror e aos terroristas, que, em rigor, não passa do "mais do mesmo" já descrito de identificação do inimigo e tudo que se segue a isso. Contudo, a identificação do terror tem duas características ímpares de fundamental importância que valem a pena serem discorridas ligeiramente mais amiúde.

A primeira delas é que, apesar do estereótipo do árabe, o combate ao terror não se volta a uma nacionalidade específica, o que constitui, por assim dizer, um grande trunfo dos que endossam essa política. O terrorismo é a guerra de quem não pode fazer guerra, assim como a guerra é o terrorismo de quem não pode fazer terror. Essa frase é central. Trocando em miúdos, os terroristas - ou pelo menos essa é a visão do Direito Penal do Inimigo não podem guerrear. Logo, não fazem jus às convenções e tratados - e consequentes direitos - de guerra. Não são guerreiros, não são soldados. São, na verdade, vida nua, como diz Agamben ${ }^{14}$. Do outro lado, a "guerra ao terror"

\footnotetext{
${ }^{13}$ BORRADORI, Giovanna. Filosofia em tempo de terror: diálogos com Habermas e Derrida. 5. ed. Rio de Janeiro: J. Zahar Editor, p. 108.

${ }^{14}$ Cf. AGAMBEN, Giorgio. Homo sacer: poder soberano e a vida nua. 2. ed. Belo Horizonte: Editora UFMG, 2011.
} 
nada mais é do que combater o terror com o próprio terror - a violência com mais violência -, só que mascarado, porque os aliados, os amigos, não podem fazer terror. Em suma, revela-se a grande contradição do que é, pelos fortes, uso legítimo da força; pelos fracos, terrorismo.

A segunda característica é especialmente importante e até curiosa. Advém exatamente do léxico. Terrorismo, terror. A palavra já carrega toda a carga semântica necessária. O termo em que todo esse discurso é construído nos remete novamente a Umberto $\mathrm{Eco}^{15}$ e à discussão medieval em torno das ideias universais, ou seja, se o que vale mais são as coisas ou o nome que lhes emprestamos. Há uma tradição em determinado texto canônico no qual se leria que nomes seriam mais importantes do que coisas, afinal, diz, no dia em que no mundo não existirem mais rosas, restará entre os homens a lembrança do nome da rosa. E terror é certamente o nome mais adequado, o que mais serve ao discurso do Direito Penal do Inimigo, o aperfeiçoado toque moderno desse pensamento secular.

Outrossim, é importante colocar que tudo isso tem como bandeira a chamada segurança nacional, que incorpora e sintetiza os discursos nacionalista e do medo, e que não deixa de ser também um termo extremamente apelativo para fazer frente ao terrorismo. E em meio a essa política criminal que se volta contra o inimigo, grandes pontos se colocam. De início tem-se, claramente, a indagação sobre a legitimidade, ou não, de o poder estatal negar àqueles que, dentre o corpo social, são eleitos como os inimigos e, por meio desta acepção, garantir a alguns certos direitos e garantias que a outros são ampla e deliberadamente negados, convertendo-se o estável para o incerto, o cidadão para inimigo; negando eficácia, e existência de direitos universais e próprios dos Estados democráticos.

Colocam-se em risco, desse modo, as próprias bases dos atuais regimes democráticos e seus ideais constitucionais de liberdade e igualdade, por exemplo. A partir de um marco histórico como o 11 de setembro e das questões concernentes à prática terrorista e a segurança nacional, se deram as reações políticas e jurídicas, principalmente de ordem legislativa, a esse fenômeno. Faz-se necessário se pensar, portanto, em que medida elas po-

${ }^{15}$ Cf. ECO, Umberto. O nome da rosa. Rio de janeiro: Globo, 2003. dem ou não ser sustentadas em um cenário de Estado que se afirma Democrático de Direito, bem como se questionar acerca da possibilidade de se conciliar, por exemplo, uma política criminal como o Direito penal do Inimigo e a universalidade de direitos e garantias fundamentais que hoje se defende, refletindo sobre até que ponto essa segurança proposta é realmente alcançada e quando ela se torna uma ameaça, e não uma garantia, ao corpo social e político.

\section{Direito Penal do Inimigo como reação às práticas terroristas: interferências nas legislações global e brasileira}

Analisando-se as influências do terrorismo e da "resposta político-normativa" defendida, entre outros, por Jakobs, é interessante notar que o processo de construção normativa, visto de uma maneira ampla e global, já estava atento a essa questão muito antes dos atentados de 11 de setembro, mas é a partir desse fato e da disseminação de correntes como a do já mencionado Direito Penal do Inimigo que ocorre a efetiva legitimação desse tipo de lei. Na legislação brasileira vigente, apesar de encontrarmos indícios de discriminação de um inimigo social pelo Código Penal através de alguns crimes, não é possível vislumbrar claramente dentro desse diploma legal o inimigo em si da maneira como é possível na tipificação pelos crimes contra a segurança do Estado que hoje vigoram na legislação extravagante. Muito desse fato se deve a Nelson Hungria, autor do anteprojeto do Código Penal de 1940, que se demonstrou abertamente contrário ao modo como o Direito Penal fascista e o nazista concebiam esses delitos ${ }^{16}$.

Em relação a essa matéria, vigora no ordenamento brasileiro a lei 7.170/83, a Lei de Segurança Nacional. As preocupações com a dita segurança nacional que culminaram nessa lei eram de ordem estritamente interna, baseadas em uma Doutrina de Segurança Nacional consolidadas na ânsia pelo combate ao comunismo ${ }^{17}$, mudada drasticamente pelo advento da Constituição de 1988 e pelos atos terroristas do início do século XXI.

\footnotetext{
${ }^{16}$ ECO, Umberto. O nome da rosa. Rio de janeiro: Globo, 2003. p. 265.

${ }^{17}$ Ibidem, p. 280
} 
Com a promulgação da Constituição de 1988, reacendeu-se a discussão acerca da existência da tipificação do crime de terrorismo, não só pelo fato de, no ordenamento como hoje se encontra, não haver nenhum delito com nomen iuris "terrorismo", tampouco pelo fato de as condutas relacionadas no tipo penal descrito no artigo 20 da lei $7.710^{18}$ irem, de certo modo, em sentido contrário ao consolidado princípio da legalidade, mas, sim, porque começou-se a se questionar a possibilidade desse artigo ter sido revogado tacitamente com a promulgação da nova Constituição. Sobre o segundo ponto elencado acima, questiona-se muito a amplitude da expressão "atos de terrorismo"; em relação ao último, os favoráveis à tese de revogação afirmam que, pelo fato de os núcleos do tipo estarem submetidos à exigência de dois dolos específicos inconstitucionais, todo esse tipo penal deve ser considerado inconstitucional.

Utilizando-se das ideias de Heleno Cláudio Fragoso sobre as condutas típicas do art. 28 da lei 6.620, de 17 de dezembro de 1978 - com redação semelhante ao tipo acima mencionado -, Fernando Capez afirma que, a despeito da amplitude com que se é possível entender a expressão "atos de terrorismo", tal dispositivo não é inconstitucional por estar equiparada a essa conduta os demais núcleos do tipo. Assim, por se tratar de um crime de ação múltipla, basta que qualquer outro ato assemelhado seja executado. Cumpre-se ressaltar que, para esse autor, "o largo alcance da elementar em questão é perfeitamente aceitável"19. A despeito de esse argumento favorável à constitucionalidade do dispositivo em questão ser bastante convincente, deve-se esclarecer que ele constitui um argumento a mais para aqueles que afirmam que não há o crime de terrorismo na legislação brasileira. Afinal, se não há incriminação pela prática de atos de terrorismo, mas pela prática dos outros núcleos, quando as condutas de um sujeito delitivo incorrem nessa tipificação

${ }^{18}$ Art. 20 - Devastar, saquear, extorquir, roubar, seqüestrar, manter em cárcere privado, incendiar, depredar, provocar explosão, praticar atentado pessoal ou atos de terrorismo, por inconformismo político ou para obtenção de fundos destinados à manutenção de organizações políticas clandestinas ou subversivas.

Pena: reclusão, de 3 a 10 anos.

Parágrafo único - Se do fato resulta lesão corporal grave, a pena aumenta-se até o dobro; se resulta morte, aumenta-se até o triplo. penal, não há como afirmar que ocorreu um crime de terrorismo.

Porém, o maior problema que envolve esse dispositivo reside no terceiro ponto que elencado. O contexto no qual esse tipo foi elaborado é totalmente diferente o atual. Enquanto naquela época - 1978 -, ao governo restavam ações políticas estritamente voltadas ao bem comum do próprio governo, hoje em dia, embora a preocupação constitucional ainda esteja fortemente marcada por essa característica, o crescimento do rol de garantias individuais não permite mais aceitar certos dispositivos legais que outrora vigoraram no ordenamento. Sob essa perspectiva, os dolos específicos citados não podem ser ditos constitucionais por dois principais motivos.

Em primeiro lugar, por se tratar de um daqueles textos em que os princípios e as ideias ali presentes se destacam mais que as próprias palavras que ali figuram, a Constituição de 1988, sob a patrocínio dos ideais de um Estado Democrático de Direito e da liberdade de expressão ao qual esse deve conferir aos seus cidadãos, não pode aceitar a possibilidade de existirem organizações políticas clandestinas ou subversivas. Mesmo aqueles que possuem uma leitura constitucional mais literal devem concordar que o texto constitucional conferiu tratamento muitíssimo diferenciado às organizações políticas, sendo vedadas apenas as associações de caráter paramilitar, nos termos do art. $5^{\circ}$, XVIII. Não há mais a possibilidade de se pensar em organizações políticas clandestinas ou subversivas senão aquelas de caráter paramilitar. Assim, a não ser que a finalidade da conduta cometida seja voltada para manutenção organização política subversiva de caráter paramilitar, não há como vislumbrar a presença desse tipo de injusto especial.

Em segundo lugar, dentro das perspectivas principiológicas já destacadas, o "agir por inconformismo político" é um dos pilares do Estado Democrático de Direito. $\mathrm{O}$ debate, o questionamento constante é inerente à democracia. É o exercício democrático em pleno funcionamento. Deste modo, vai contra a principiologia do texto constitucional incluir essa ideia no tipo subjetivo de um delito, principalmente em um daqueles elencados na Lei de Segurança Nacional, que deveria proteger os cidadãos dentro de um ideal de bem comum e não o bem comum em detrimento dos cidadãos. Uma vez mais, relativizamse princípios e direitos que não são absolutos, mas rígidos o bastante para conter esse tipo de interpretação. 
Diante da iminente reforma do Código Penal, é interessante notar as perspectivas legislativas em torno dessa matéria. Tratando-se de proposições legislativas que alterem essa tão questionada lei, destacam-se o Projeto de Lei da Câmara - PLC - 2462/1991, o PLC 6764/2002 a ele apensado, o PLC 486/2007, o PLC 1558/2011 e o Projeto de Lei do Senado 707/2011. Não coincidentemente, é claro, observa-se um boom legislativo no Brasil nesse campo após os atentados terroristas do início do século XXI. Contudo, apesar da tentativa de retificar os problemas que a legislação sobre terrorismo apresenta hoje, são muitos as críticas a todos esses projetos acima, que, de certo modo, podem ser consideradas críticas globais às leis que tratam do assunto após o 11 de setembro - isto é, não são críticas exclusivas ao legislador brasileiro.

Pegue-se o caso americano: no art. 802 do Patriot Act, define-se "terrorismo interno" como atos que colocam em perigo a vida humana através de violações do direito penal e voltados à política de um governo através de intimidação ou coerção ${ }^{20}$. Da forma como foi redigido, os movimentos sociais que vierem a danificar bem de propriedade pública podem vir a ser enquadradas por esse tipo penal, mesmo caminho, percebe-se, trilhado pelos projetos brasileiros. Aliás, nos demais países, a evolução da tipificação da conduta de terrorismo tem seguido essa mesma linha delineada pelo Patriot Act. Condizente com essa observação, Habermas afirma que a ameaça de terrorismo global acelerou a necessidade de uma transformação da lei internacional clássica em uma nova ordem cosmopolita em escala mundial ${ }^{21}$ - estabelecendo uma espécie de bem jurídico internacionalmente tutelado. Interessante notar que até a ocorrência dos atentados de 11 de setembro, somente França, Alemanha, Itália, Portugal, Espanha, Grécia e Reino Unido mencionavam o termo terrorismo em seus instrumentos jurídicos ${ }^{22}$. Muito menos ligado à questão da segurança global, esse termo tinha o cunho de, através do Direito Penal comum, proteger os indivíduos dos ataques provenientes de grupos separatistas como o IRA e o ETA

${ }^{20}$ CAPEZ, Fernando. Curso de direito penal: legislação penal especial. 3. ed. São Paulo: Saraiva, 2008. v. 4. p. 304.

${ }^{21}$ BORRADORI, Giovanna. Filosofia em tempo de terror: diálogos com Habermas e Derrida. 5. ed. Rio de Janeiro: J. Zahar Editor, p. 63.

${ }^{22}$ DAL RI JUNIOR, Arno. O Estado e seus inimigos: a repressão política na história do Direito Penal. Rio de Janeiro: Revan, 2006.
- novamente, terrorismo estava ligado estritamente às questões de ordem interna.

A consolidação de um novo tipo de terrorismo, global, voltado a explorar a vulnerabilidade de sistemas complexos $^{23}$, pode ser tido como um dos fatores que motivaram o processo legislativo global a "modernizar" o tratamento dado a essas condutas. Todavia, apesar desses esforços, pela complexidade da matéria e do período em que foram elaborados, muitos textos legais foram controversos, como "direito a legítima defesa coletiva”. $\mathrm{Na}$ verdade, a utilização dessa e de outras expressões - como "direito à resposta" - visa, sem sombra de dúvidas, a necessidade de legitimação legal de um "direito à vingança" da comunidade global, de que não escapou nem mesmo a resolução da ONU n ${ }^{\circ} 1.368^{24}$, aprovada poucos dias após o incidente das torres gêmeas. Afinal de contas, além de ser inimaginável pensar em legítima defesa desencadeada por um ato que já exauriu todos seus efeitos na esfera jurídica, o que a própria ONU entende por legítima defesa coletiva é a retaliação sem deliberação do Security Council de um Estado que recebeu um ataque armado de outro $^{25}$. Vendo os itens 3, 4 e 5 dessa resolução ${ }^{26}$, nota-se um convite da ONU à comunidade global para responder aos ataques de 11 de setembro.

Portanto, tanto no âmbito internacional quanto no âmbito doméstico de cada país, são claras as tendências legislativas que se aproximam do Direito Penal do Inimigo. Muito disso, é claro, deve-se ao período de Exce-

${ }^{23}$ BORRADORI, Giovanna. Filosofia em tempo de terror: diálogos com Habermas e Derrida. 5. ed. Rio de Janeiro: J. Zahar Editor, p. 68.

${ }^{24}$ ONU. Disponível em: <www.unhchr.ch/Huridocda/Huridoca.nsf/(Symbol)/ S.RES.1368+(2001).En?Opendocument> .

${ }^{25}$ Disponível em: <http://academico.direito-rio.fgv.br/ wiki/Aula_15_-_2010.2:_A_leg\%C3\%ADtima_defesa_ como_exce\%C3\%A7\%C3\%A3o_do_uso_unilateral_da_ for\%C3\%A7a.> Acesso em: dia mês abreviado e ano.

26 3. Calls on all States to work together urgently to bring to justice the perpetrators, organizers and sponsors of these terrorist attacks and stresses that those responsible for aiding, supporting or harbouring the perpetrators, organizers and sponsors of these acts will be held accountable;

4.Calls also on the international community to redouble their efforts to prevent and suppress terrorist acts including by increased cooperation and full implementation of the relevant international anti-terrorist conventions and Security Council resolutions, in particular resolution 1269 (1999) of 19 October 1999;

5.Expresses its readiness to take all necessary steps to respond to the terrorist attacks of 11 September 2001, and to combat all forms of terrorism, in accordance with its responsibilities under the Charter of the United Nations 
ção que as grandes potências globais se encontraram no início do século XXI. Todavia, até que ponto isso é uma justificativa? Para Agamben, aliás, falar em Estado de Exceção, de período de Exceção é contradizer os próprios fundamentos da soberania, ou seja, para esse filósofo italiano, todo Estado é um Estado de Exceção. Diante de tal pensamento, invalida-se a justificativa - a desculpa - desse movimento legislativo baseada no contexto em que as leis foram editadas, afinal, a todo tempo estamos em "exceção soberânica" - não se pode atribuir uma relação de causa e consequência entre o contexto e a edição legislativa se o primeiro está sempre presente em todas as hipóteses de elaboração normativa.

Desta forma se entende problemática a tipificação de um crime de "atos de terrorismo". A identificação do inimigo por si só já é problemática, bem como a delimitação do que efetivamente sejam "atos terroristas", tendo em vista a indefinição semântica do que de fato seja terrorismo. Considerando que todo conceito é, na verdade, atemporal e ahistórico, o máximo que se pode falar ao se pensar em terrorismo é estar diante de uma noção, que só pode ser pensada em um momento singular, a partir de uma visão histórica e contextual. Foi o que disse o então ministro do Supremo Tribunal Federal Nelson Jobim no julgamento da Extradição 855, afirmando que o terrorismo "[...] não é um conceito que diz respeito a um ato da realidade, não é um substantivo que trate de atos concretos; são juízos de valores em condutas políticas que têm de ser examinados caso a caso". Deixando ao termo tamanha amplitude, não restaria lugar, por exemplo, para a qualificação de um ato como de "crime político", já que é tênue a linha que divide essas duas esferas e, a rigor do que prescreve o inciso LII do art. $5^{\circ}$, implica em sérias consequências materiais.

Não obstante, de acordo com a Agência Senado, o anteprojeto afirma que será considerado terrorismo "causar terror na população" mediante condutas como sequestrar ou manter alguém em cárcere privado; usar ou portar explosivos, gases tóxicos, venenos, conteúdos biológicos ou outros meios capazes de causar danos; incendiar, saquear, explodir ou invadir qualquer bem público ou privado; e interferir, sabotar ou danificar sistemas de informática e bancos de dados. Considerou-se também a conduta de sabotar o funcionamento ou apoderar-se, entre outros, do controle de comunicação ou de transporte de portos, aeroportos, hospitais, casas de saúde, escolas, instalações públicas ou locais onde funcionem serviços públicos essenciais, inclusive instalações militares. Irônico que nessa própria tentativa de fechar o conteúdo semântico dos "atos de terrorismo" é possível notar sua impossibilidade: prevê-se um imenso rol de atitudes, mas não se esgota o tipo penal, deixando-o ainda aberto, algo igualmente notado na tentativa de prever aquilo que não poderá ser considerado como terrorista.

Fácil notar, tal como até o STF já se pronunciou, que tentar definir o que é ou não terrorista é, portanto, fazer um juízo de valor acerca de certas circunstâncias que dependem estas mesmas dos juízos de valores feitos por quem tenta analisá-las e da própria sociedade na qual tem lugar essa análise. Ora, não é suficiente, baseado em um conceito aberto, indefinido e fundamentado em juízos de valores, restringir o exercício e a aplicabilidade de direitos e garantias tidas como fundamentais, sobrepujando a legalidade.

Vê-se, no âmbito brasileiro, a incorporação de um discurso e ideal recentemente predominante no mundo ocidental de que vivemos perigosos tempos, e que a sociedade, e também o direito, devem se adaptar a isso, justificativa, por exemplo, dos líderes da Comissão de Reforma. Ora, nada mais sadio para a sociedade do que consolidar nas leis os ideais garantistas baseados não só na legalidade, mas também em uma filosofia política que requeira do Direito e do Estado o ônus de justificação externa atrelado aos interesses dos quais a tutela constitui finalidade ${ }^{27}$. Cabe à lei, através de um processo racional, limitar e minorar a fragilidade intrínseca do indivíduo nessa relação com o seu Leviatã, nunca o contrário - aumentar a fragilidade daquele.

\section{A problemática do Direito Penal do Inimigo}

Os direitos e garantias individuais são conquistas muito caras histórica e juridicamente. São resultados de séculos de lutas, considerados genericamente como inerentes à qualidade humana e se tem despendido um esforço comum no sentido de universalização dos direitos fundamentais. Aliás, é em nome deles e de princípios tidos como democráticos que se balizaram algumas das

\footnotetext{
${ }^{27}$ FERRAJOLI, Luigi. Direito e razão: teoria do garantismo penal. São Paulo: Revista dos Tribunais, 2002. p. 785-786.
} 
ações internacionais de grandes potências (como a invasão do Iraque por tropas norte-americanas). Nessa contextura se coloca uma grande questão: pode-se, em nome de um bem maior e, sob certo aspecto, transcendental (tal como a "segurança nacional", que parece ter o condão de justificar qualquer política) negar direitos e garantias a pessoas tidas por terroristas? E mais: como distinguir um terrorista; como distingui-lo e separá-lo dos cidadãos? Um exemplo concreto: é possível distinguir um ato terrorista de um crime político? O que justifica o tratamento extremamente díspare a cada um destes, levando em conta que são, em essência, objetivamente falando, condutas bastante próximas?

Vivemos, como já foi dito, um contexto de expansão do direito penal. Como solução de problemas das mais diversas ordens que, até então, eram considerados indiferentes à tutela penal: a subsidiariedade e a intervenção mínima, características penais basilares, foram relativizadas. Nos dizeres de Silva Sanchez, tal expansão se dá em duas velocidades: uma primeira, mais antiga, relacionada ao setor do ordenamento jurídico no qual se impõem as penas privativas de liberdade e, portanto, tratando-se de restrições ao direito de liberdade dos indivíduos, faz-se necessário, em tal cenário, a estrita observância das garantias individuais, tais como os princípios processuais (contraditório, ampla defesa, etc.). A segunda velocidade, mais recente, se volta contra o criminoso dito menos habitual, isto é, àqueles que cometem delitos de ordem fiscal, tributária, ambiental, por exemplo, para os quais se atribuem, em geral, penas pecuniárias ou restritivas de direito, formando um contexto no qual se entende possível uma flexibilização dos princípios e regras clássicos.

Discriminadas essas duas velocidades, dentro dessa perspectiva, o surgimento do Direto Penal do Inimigo se daria como uma perigosa terceira velocidade de coexistência das penas privativas de liberdade e da flexibilização de princípios político-criminais e regras de imputação. Surgem assim elementos como o adiantamento da punibilidade, a aplicação de penas altas e desproporcionais, a minimalização e até a supressão de garantias processuais, o uso de provas ilícitas, dentre outros, os quais restringem a titularização de direitos e garantias aos ditos inimigos. Há, dentro dessa perspectiva, uma cisão entre o cidadão e o inimigo, provocando uma necessária bipolarização do Direito Penal: um polo voltar-se-ia ao cidadão, otimizando esferas de liberdade e priorizando as garantias legal e constitucionalmente previstas; outro, ao inimigo, relativizando essas afirmações em nome da proteção a certos bens jurídicos.

Para esclarecer melhor, analisando-se também o panorama internacional, retome-se, na doutrina de Jakobs, o inimigo, o que insiste em descumprir o ordenamento jurídico-penal, colocando em risco o próprio ordenamento e a sociedade, aproximando-se de teorias contratualistas e iluministas, afirmando que o inimigo se atribui seu próprio status ao descumprir o contrato social, renunciando a seu estado de cidadão. Diante de tal escolha - frise-se, puramente desfundamentada e abstrata -, não caberia ao Estado outra opção senão a de lhe conferir tratamento diferenciado, visando, por meio do uso da força (já que Direito é força), a eliminar os inimigos e os riscos que esses trazem, proposta conflitante com os pilares do constitucionalismo contemporâneo (o qual preza pela dignidade da pessoa humana e universalidade dos direitos fundamentais), o que enseja grande preocupação: agindo desse modo, rompe-se com direitos e garantias essenciais em prol de um sistema baseado na periculosidade abstrata sem limitações ao poder punitivo; rechaçando o princípio da lesividade; gerando uma reaproximação com o direito penal do autor, o qual se volta majoritariamente não para os elementos da conduta praticada e do fato realizado, mas para as características daquele que a cometeu.

Tal corrente se fortaleceu após a ocorrência, nos últimos anos, de atentados terroristas que, sem dúvida, trouxeram à população mundial não só prejuízos materiais, bem como modificaram, por completo, as relações internacionais e as políticas de segurança nacional dos países. Dentro desse campo, tem-se, como inegável marco, os acontecimentos do 11 de setembro, do qual foram vítimas, deixando aqui as teorias conspiratórias de lado, os Estados Unidos. Esse fato provocou, no âmbito do agir político e jurídico das nações, alterações legislativas e de política externa, com fins a prevenir novos ataques e conter a fluida e invisível ameaça terrorista.

É possível, no âmbito da política externa, perceber que houve uma total modificação na geopolítica mundial: formou-se uma coalizão que, baseada na conhecida "Doutrina Bush", lançou-se em uma Guerra Contra o Terror, pela qual se intentava acabar com qualquer célula dita terrorista ao redor do mundo, ou, como dizia o então presidente George W. Bush em mais uma expressão dig- 
na de nota, acabar com o "Eixo do Mal". Alguns países, tais como Afeganistão, Iraque e Irã, foram eleitos como os principais loci de tais grupos, e criou-se, no campo da comunidade internacional, um clima de tensão. Entretanto, é no campo das mudanças legislativas que emergem os principais problemas: são esses atos legislativos que colocam em risco e ameaçam os direitos e garantias individuais e fundamentais atribuídos, universalmente, a todos àqueles que, pelo simples fato de serem humanos, merecem um tratamento digno. Várias nações começaram a editar atos normativos que passaram, entre outras medidas, a conferir penas mais duras a atos ditos terroristas. Além disso, deu-se também a

criminalização de práticas que possam significar danos a uma coletividade, ampliação dos poderes dos órgãos de investigação internos e das agências de espionagem, diminuição das garantias processuais dos acusados, redução da possibilidade de supervisão, pelo Poder Judiciário, das atividades policiais, aumento da confidencialidade dos procedimentos policiais e judiciais e aumento do prazo de detenção provisória, a depender do grau de ameaça que um ou mais suspeitos possam representar à segurança nacional ${ }^{28}$.

Dentre essas referidas medidas legislativas, tem destaque o USA Patriot Act ${ }^{29}$, um ato do Congresso norte-americano sancionado pelo ex-presidente Bush em 26 de outubro de 2001, pouco tempo depois dos conhecidos ataques terroristas. Além disso, nessa mesma contextura, se colocam os debates acerca da Base Militar de Guantánamo, que deixam muito claro fundamentalmente a situação singular de despidos de direitos dos detentos, como revelam a alimentação e medicação forçadas de presos em greve de fome, a tortura propriamente dita, o total distanciamento do devido processo legal e abdicação do contraditório, com advogados sendo indicados pelo executivo, julgamentos por tribunais militares sem direito a recurso em tribunais civis (até o caso Boumediene versus Bush, em que a Suprema Corte dos Estados Unidos de-

${ }_{28}^{28}$ PAIXÃO, Cristiano. Terrorismo, direitos humanos e saúde mental: o caso do campo de prisioneiros de Guantánamo. In: COSTA, Alexandre Bernardino et al (Org.). O direito achado na rua: introdução crítica ao direito à saúde. Brasília: CEAD/ UnB, 2008, p. 383-395. p. 383.

29 "Uniting and Strengthening America by Providing Appropriate Tools Required to Intercept and Obstruct Terrorism (USA PATRIOT) Act of 2001", acrônimo que, em uma tradução livre, pode ser lido como "Unir e Fortaler a América pelo fornecimento de Ferramentas Adequadas Necessárias para a Interceptação e Obstrução do Terrorismo". cidiu que os presos têm direito à habeas corpus julgado por juízes federais), culminando no absurdo de pessoas presas mantidas sem acusação formal, sem ter do que se defenderem. Vê-se uma total abdicação dos direitos e garantias fundamentais em nome de valores abstratos e de difícil mensuração. Abre-se mão daquilo que sempre defendeu em nome de interesses políticos, fundamentando-se uma teoria que, flagrantemente, viola muitos das ideias democráticas contemporâneas que tanto custaram para serem afirmadas.

\section{Conclusão}

O desafio da inclusão é um dos principais pontos de regimes democráticos. No Estado Democrático de Direito, a titularidade de direitos individuais é conferida a todos os seres humanos, e é indisponível, tanto pelo indivíduo, quanto pelo próprio Estado. Criar-se, em nome da defesa de todos ante uma situação excepcional, um estado de exceção no qual direitos fundamentais são suspensos para alguns a fim de que sejam resguardados os direitos dos demais é claramente ilegítimo. O grande problema é que essa situação, dita excepcional, acaba por se prolongar; a exceção se torna regra; pessoas se tornam não-pessoas, destituídas de qualquer protetividade jurisdicional; cria-se também um terrorismo por parte do Estado. Na leitura derridariana, a violência originária, excepcional, fundadora de uma nova ordem (da exceção) busca se perpetuar e se constituir em violência conservadora. Políticas como o Direito Penal do Inimigo são, em essência, atos de terror quanto a uma parcela da população. Entretanto, pós 11 de setembro, fala-se em terrorismo só para aqueles atos que se voltam contra o Estado. Não se pode, contudo, em nome da proteção desse mesmo Estado violar seus próprios fundamentos, suas bases constitutivas: democracia é respeito às regras do jogo; não se pode, portanto, contrariá-las, mesmo que em nome da defesa da própria democracia.

O Direito Penal do Inimigo na insurgência transnacional do terrorismo e seu embate com a tentativa de universalização dos direitos fundamentais (traço do Constitucionalismo contemporâneo) gera pontos e contrapontos em diversas direções. É peculiarmente difícil sustentar um discurso contra um inimigo dentro desse contexto. Certamente terrorismo é uma prática danosa à sociedade global e deve ser combatida. Entretanto, esse 
combate encontra uma série de dificuldades, não podendo ser ilimitado em detrimento do indivíduo. Desse modo, deve ser restringido e mitigado pelo ideário elencado nas declarações de direitos, na manutenção de direitos como o do contraditório, da ampla defesa, da igualdade, da liberdade e de tantos outros que são ameaçados por teorias como a do Direito Penal do Inimigo. E é nesse sentido que têm caminhado os debates na comunidade internacional, de que é exemplo a sessão 59 da Comissão da Organização das Nações Unidas, ocorrida entre março e abril de 2003, a qual condicionava a atuação dos Estados no combate ao terrorismo ao respeito dos compromissos e obrigações assumidos tanto internacionalmente, via acordos e tratados internacionais, quanto internamente em suas leis e Constituições.

Todo esse contexto global de insegurança difusa tem sido usado como escopo para a formulação de políticas criminais como o Direito Penal do Inimigo, o que pode ser sentido, de forma cada vez mais forte e explícita, no Brasil, fato do qual a inclusão do crime de "atos de terrorismo" no anteprojeto do novo Código Penal é exemplo. Cria-se assim um discurso (muitas vezes incorporado pela população) que visa à legitimação de uma conduta violenta e agressiva por parte do Estado, o qual segrega sua população entre inimigos e cidadãos, fazendo com que uns possuam mais cidadania que outros. Ora, não se pode criar um segmento diferenciado do ordenamento jurídico o qual não se submeta aos expressos ditames constitucionais de dignidade da pessoa humana. A própria percepção do risco é um construto social, que depende de uma série de fatores mutáveis e subjetivos, traços que jamais serão suficientes para justificar tamanha intervenção nas respectivas esferas individuais de direitos dos inimigos, que são, na verdade, membros de grupos cuja identidade social, dentro de um grupo maior, é extremamente vulnerável, superando uma mera lesão a determinado bem jurídico. Vê-se aí um problema de inclusão, e uma aplicação simbólica do ordenamento penal.

Tem-se, em suma, um conflito de ideias no qual se destacam duas posições principais: de um, a afirmação dos direitos humanos e sua universalidade; de outro um discurso que prima pela integridade territorial e segurança nacional e que, em nome desses valores, acaba por atropelar certos direitos individuais e coletivos, esquecendo-se da existência de uma forma de terrorismo exercido pelo próprio Estado perante seus cidadãos. E é assim, e por todo o exposto, que se faz evidente a inviabilidade de tipificação de um delito de "terrorismo". Ao fazê-lo, admitir-se-ia, formal e explicitamente todas essas diferenças de tratamento entre inimigo e cidadão que são nitidamente contrárias ao que se defende em nosso ordenamento jurídico, tendo em vista o texto da Constituição Federal de 1988 e os direitos e princípios por ela adotados.

Novamente, "trata-se sempre de limitar a pior violência por outra" ${ }^{30}$, lembra Derrida. Verdade que o retributivo do Direito Penal é inafastável, e é a retribuição justamente a medida da sanção. Porém, se, por um lado, norma sem sanção é inócua, sanção sem regra, sem respeito às regras (como o Direito Penal do Inimigo), é abuso, este sim, mais do que qualquer delito, intolerável e fundamentalmente ilegítimo, porque contrário à Constituição, garantidora, fundadora e legitimadora do Estado e da ordem normativa, por excelência.

A beleza dos direitos fundamentais está justamente no fato de que eles devem ser assegurados a todos e a cada um; sem exceção, sem segregação, mesmo que em nome de uma abstração chamada segurança nacional. A problemática da qual se tratou é assunto que deve preocupar as autoridades de um modo geral, bem como a população que, muitas vezes iludidas por um discurso de defesa da nação e da sociedade civil, deixa passar grosseiras violações a direitos que lhes são dados como indisponíveis. Não se pode sustentar um Direito Penal do Inimigo: seus fundamentos contrariam todos os princípios fundantes do Estado Democrático de Direito e do Constitucionalismo Contemporâneo. Deve-se primar pela manutenção dos direitos individuais, das garantias constitucionais, das liberdades democráticas: afirmar o contrário seria um grande, e indesejável, retrocesso, consagrando-se, em última análise, a pior violência.

\section{Referências}

AGAMBEN, Giorgio. Homo sacer: o poder soberano e a vida nua. 2. ed. Belo Horizonte: Editora UFMG, 2011.

BAUMAN, Zygmunt. Em busca da política. Trad. Marcus Penchel. Rio de Janeiro: J. Zahar Editor, 2000.

\footnotetext{
${ }^{30}$ DERRIDA, Jacques. Força de lei: o fundamento mítico da autoridade. São Paulo: WMF M. Fontes, 2010. p. 115.
} 
BITENCOURT, Cezar Roberto. Tratado de direito penal: parte especial 5. ed. São Paulo: Saraiva, 2011.

BITENCOURT, Cezar Roberto. Tratado de direito penal: parte geral. 16. ed. São Paulo: Saraiva, 2011.

BORRADORI, Giovanna. Filosofia em tempo de terror: diálogos com Habermas e Derrida. 5. ed. Rio de Janeiro: J. Zahar Editor, [2004].

BRASIL, Supremo Tribunal Federal. EXT 855/Chile. Relato: Min. Celso de Mello. Julgamento em 26/08/2004; publicado no DJ de 01/07/2005. Disponível em: $<$ http://redir.stf.jus.br/paginadorpub/paginador.jsp? docTP=AC\&docID=325004>. Acessado em: 12 fev. 2012.

BRASIL. Constituição da República Federativa do Brasil de 1988. Disponível em: <http://www.planalto.gov.br/ ccivil_03/Constituicao/Constitui\%C3\%A7ao.htm >. Acessado em 05 fev. 2012.

BRASIL. Lei de Segurança Nacional. Disponível em: <http://www.planalto.gov.br/ccivil_03/leis/L7170.htm>. Acessado em 05 fev. 2012.

CAPEZ, Fernando. Curso de direito penal: legislação penal especial. 3. ed. São Paulo: Saraiva, 2008. v. 4.

DAL RI JUNIOR, Arno. O Estado e seus inimigos: a repressão política na história do Direito Penal. Rio de Janeiro: Revan, 2006.
DERRIDA, Jacques. Força de lei: o fundamento mítico da autoridade. São Paulo: WMF Martins Fontes, 2010.

DWORKIN, Ronald. Levando os direitos a sério. 3. ed. São Paulo: WMF M. Fontes, 2010.

ECO, Umberto. O Fascismo Eterno. In: AGUIAR, Eliane; ECO, Umberto. Cinco Escritos Morais. Rio de Janeiro: Record, 2000.

ECO, Umberto. O nome da rosa. Rio de janeiro: Globo, 2003.

FERRAJOLI, Luigi. Direito e razão: teoria do garantismo penal. São Paulo: Revista dos Tribunais, 2002.

JAKOBS, Gunther. Direito penal do inimigo: noções e críticas. Tradução de Manuel Cancio Meliá. Porto Alegre: Livr. do Advogado, 2009.

JAKOBS, Gunther. Terroristas como pessoas no direito? Novos estudos cebrap, São Paulo, n. 83, p. 27-36, mar. 2009.

PAIXÃO, Cristiano. Terrorismo, direitos humanos e saúde mental: o caso do campo de prisioneiros de Guantánamo. In: COSTA, Alexandre Bernardino et al (org.). $O$ direito achado na rua: introdução crítica ao direito à saúde. Brasília: CEAD/UnB, 2008, p. 383-395. 